\title{
Direct Absorb bioresorbable scaffold implantation in acute coronary syndrome
}

\author{
Łukasz Rzeszutko $^{1 *}$, Michał Węgiel ${ }^{1,2 *}$, Paweł Kleczyński ${ }^{1,3}$, Wojciech Zasada ${ }^{1}$, Rafał Depukat ${ }^{1}$, \\ Tomasz Rakowski ${ }^{1,3}$, Jacek Legutko ${ }^{2}$, Andrzej Surdacki ${ }^{3}$, Dariusz Dudek ${ }^{1,3}$, Stanisław Bartuś $\hat{s}^{1,3}$ \\ $12^{\text {nd }}$ Department of Cardiology and Cardiovascular Interventions, University Hospital, Krakow, Poland \\ ${ }^{2}$ Institute of Cardiology, Jagiellonian University Medical College, Krakow, Poland \\ ${ }^{3} 2^{\text {nd }}$ Department of Cardiology, Jagiellonian University Medical College, Krakow, Poland \\ *Dr. Łukasz Rzeszutko and Dr. Michał Węgiel contributed equally to this work and are joint first authors.
}

\begin{abstract}
A b stract
Background: Direct stent implantation is a preferred technique for primary percutaneous coronary intervention ( $\mathrm{PCl}$ ). For the deployment of a bioresorbable vascular scaffold (BVS), the current guidelines recommend aggressive predilatation. Data about direct BVS implantation in patients with acute coronary syndrome (ACS) are scarce.

Aim: We sought to assess procedural characteristics and immediate outcomes of direct Absorb BVS implantation in ACS patients.

Methods: A total of 91 patients with acute myocardial infarction (MI) requiring urgent coronary revascularisation were enrolled. Among them, 50 patients underwent an attempt of direct Absorb implantation. The control group consisted of 41 patients treated with $\mathrm{PCI}$ with BVS deployment after elective predilatation.

Results: In the direct group BVS deployment was successful in $91 \%$ of lesions, and in the remaining $9 \%$ of lesions direct implantation failed. In the control group scaffolds were successfully deployed after predilatation in $98 \%$ of lesions. In one case Absorb implantation failed even after balloon angioplasty. Type C lesions with severe tortuosity and angulation $>90^{\circ}$ were associated with failure in direct Absorb deployment. Quantitative coronary analysis showed similar final percentages of diameter stenosis in the study and control groups. Flow analyses did not show significant differences between both methods. During hospitalisation no recurrent $\mathrm{MI}$, scaffold thrombosis, or target lesion revascularisation was reported in either group.

Conclusions: Direct Absorb implantation in ACS patients may be feasible in a suitable lesion anatomy.

Key words: acute coronary syndrome, angioplasty, direct stenting, bioresorbable vascular scaffold
\end{abstract}

Kardiol Pol 2018; 76, 10: 1434-1440

\section{INTRODUCTION}

Absorb is an everolimus-eluting bioresorbable vascular scaffold (BVS; Abbott Vascular, Santa Clara, CA, USA). Current recommendation for BVS implantation is plaque preparation with adequate predilatation $[1,2]$. On the other hand, in the setting of large thrombus burden, aggressive predilatation may result in an increased risk of distal embolisation and subsequent flow deterioration [3]. There are scarce data in terms of the feasibility and safety of direct stenting with Absorb BVS [4, 5]. So far, there has been no specific evaluation of this approach in patients presenting with acute coronary syndrome (ACS). The aim of the current study was to assess procedural characteristics and angiographic results of direct BVS deployment in ACS patients.

\section{METHODS}

Study population and procedure

The presented single-centre study is an analysis of 91 patients with acute myocardial infarction (MI) treated with primary percutaneous coronary intervention $(\mathrm{PCl})$ with Absorb BVS implantation. A total of 50 patients underwent an attempt of direct Absorb implantation. The control group consisted of 41 patients treated with $\mathrm{PCl}$ with Absorb deployment after elective predilatation. Angiographic data were assessed by an

\section{Address for correspondence:}

Stanisław Bartuś, MD, PhD, $2^{\text {nd }}$ Department of Cardiology, Jagiellonian University Medical College, ul. Kopernika 17, 31-501 Kraków, Poland, tel: +48 12 424 7181 , fax: +48 1242471 84, e-mail: stanislaw.bartus@uj.edu.pl

Received: 21.04.2018 Accepted: 3.07.2018 Available as AoP: 5.07.2018

Kardiologia Polska Copyright (C) Polish Cardiac Society 2018 
Table 1. Demographic and baseline clinical characteristics

\begin{tabular}{|c|c|c|c|}
\hline & Direct (50 patients) & Predilatation (41 patients) & $\mathbf{p}$ \\
\hline Age [years] & $60 \pm 10$ & $60 \pm 12$ & 0.8 \\
\hline Male sex & $38(76)$ & $36(88)$ & 0.2 \\
\hline STEMI & $19(38)$ & $12(29)$ & 0.5 \\
\hline LVEF [\%] & 55 (Q1: 45; Q3: 60) & 55 (Q1: 47; Q3: 60) & 0.5 \\
\hline Previous PCl & $2(4)$ & $4(10)$ & 0.4 \\
\hline Hypertension & $32(64)$ & $23(56)$ & 0.5 \\
\hline Hyperlipidaemia & $29(58)$ & $20(49)$ & 0.4 \\
\hline Diabetes & $11(22)$ & $5(12)$ & 0.3 \\
\hline
\end{tabular}

Data are presented as number (percentage), mean \pm standard deviation, or median (interquartile range). LVEF — left ventricular ejection fraction; $\mathrm{PCl}$ - percutaneous coronary intervention; STEMI — ST-segment elevation myocardial infarction

independent core laboratory. The study was approved by the Institutional Board of Ethics. Inclusion criteria comprised acute $\mathrm{MI}$ and referral for primary PCI with BVS implantation after a diagnostic coronary angiography. All procedures were carried out by three experienced operators (more than $1000 \mathrm{PCls}$ in ACS each). The decision whether to perform direct implantation of the Absorb or to precede it with balloon angioplasty was made by the operator after careful examination of the culprit lesion anatomy. The sizes of the chosen scaffolds and balloons for predilatation and postdilatations, inflation pressures, and the use of manual aspiration thrombectomy catheters as well as additional imaging tools such as intravascular ultrasonography (IVUS) or optical coherence tomography (OCT) were also left to the operator's discretion.

\section{Angiographic assessment}

All collected angiograms were sent to an independent Core Laboratory (KCRI, Krakow, Poland) and were examined by an analyst with experience in the evaluation of different bioresorbable platforms. Qualitative and quantitative analyses were performed using CAAS V 2.1.12.2 software (Pie Medical, Maastricht, Netherlands). Standard stent parameters were analysed: minimal lumen diameter, reference vessel diameter (RVD), per cent diameter stenosis (\%DS), acute gain, and acute recoil. The following angiographic flow parameters were examined before and after $\mathrm{PCl}$ of the infarct-related artery: epicardial antegrade flow using the Thrombolysis In Myocardial Infarction (TIMI) scale and corrected TIMI frame counts (cTFC) using standard landmarks for each artery. The American College of Cardiology/American Heart Association classification was used to define the lesions' anatomy [6].

\section{Statistical analysis}

Quantitative variables were presented using mean and standard deviation (for normal distribution of data) or median with interquartile range (for non-normal distribution of data), where applicable. Categorical variables were presented as numbers and percentages. The Mann-Whitney $U$ test (for non-normal distribution of data) or unpaired (two-sample) Student t test (for normally distributed data) were applied for continuous variables. The $\chi^{2}$ test was used for categorical (nominal and dichotomous) variables. The level of statistical significance was set at $p$-value $<0.05$. All analyses were performed with SPSS Statistics 24 (IBM, Inc., Armonk, NY, USA).

\section{RESULTS}

Clinical data are shown in Table 1. Most of the patients were male, and the most common clinical presentation was non-ST-segment elevation MI (NSTEMI). There were no significant differences in demography and coronary artery disease risk factors between both groups (Table 1). Baseline angiographic analysis showed no significant differences in lesion length, RVD, and \%DS between the direct and predilatation groups. However, type $\mathrm{C}$ lesions with severe calcifications were more common in the predilatation arm. In the direct group, total occlusion and thrombus in target lesion were more frequent (Table 2). Absorb deployment was successful in $91 \%$ of lesions in this group. In the remaining $9 \%$ of lesions direct implantation failed. In these cases, the system was gently retrieved and inserted again within a relatively short period of time (max $2 \mathrm{~min}$ ) after predilatation. In the control group scaffolds were successfully implanted in $98 \%$ of lesions. In one patient the delivery of Absorb scaffold was unsuccessful even after balloon preparation. In this case a regular metallic drug-eluting stent (DES) was successfully deployed. Type C lesions with severe tortuosity and angulation $>90^{\circ}$ were associated with failure in direct Absorb deployment (Table 3).

During $\mathrm{PCl}$, the use of extra-support coronary wires was more frequent in the predilatation arm. Postdilatation was performed in 94\% of lesions from the direct group and in $79 \%$ of lesions from the predilatation arm $(p=0.04)$. Mean postdilatation pressure was $18 \mathrm{~atm}$ in both groups. Thrombectomy was performed in $48 \%$ of cases in the direct group and $13 \%$ of cases in the predilatation arm $(p<0.001)$. Predilatation with a small-size balloon (1.5 or $2.0 \mathrm{~mm}$ ) for initial opening of the artery was performed in $17 \%$ of cases in the predilatation arm. 
Table 2. Baseline angiographic characteristics

\begin{tabular}{|c|c|c|c|}
\hline & Direct (53 lesions) & Predilatation (48 lesions) & p \\
\hline Left anterior descending location & $20(38)$ & $23(48)$ & 0.3 \\
\hline Type C lesion & $7(13)$ & $16(33)$ & 0.016 \\
\hline Severe tortuosity & $5(9)$ & $6(12)$ & 0.7 \\
\hline Severe calcifications & $0(0)$ & $5(10)$ & 0.018 \\
\hline Angulation $>90^{\circ}$ & $5(9)$ & $6(12)$ & 0.7 \\
\hline Lesion length [mm] & 13.3 (Q1: 10; Q3: 16) & $15.7(\mathrm{Q} 1: 11 ; \mathrm{Q} 3:$ 21) & 0.3 \\
\hline Minimal lumen diameter $[\mathrm{mm}]$ & 0.65 (Q1: 0; Q3: 1.03) & 0.78 (Q1: 0.13; Q3: 1.16) & 0.1 \\
\hline Reference vessel diameter [mm] & $2.8 \pm 0.5$ & $2.7 \pm 0.6$ & 0.3 \\
\hline Diameter stenosis [\%] & 78 (Q1: 59; Q3: 100) & 67 (Q1: 54; Q3: 94) & 1.0 \\
\hline Corrected TIMI frame count & 100 (Q1: 30; Q3: 100) & 30 (Q1: 24; Q3: 100) & 0.02 \\
\hline Total occlusion & $24(45)$ & $11(23)$ & 0.018 \\
\hline Thrombus in target lesion & $34(64)$ & $15(31)$ & 0.001 \\
\hline
\end{tabular}

Data are presented as percentage (number), mean \pm standard deviation, or median (interquartile range). TIMI — Thrombolysis in Myocardial Infarction

Table 3. Lesion characteristics in groups with successful and failed direct Absorb deployment

\begin{tabular}{|lccc|} 
& Successful (48 lesions) & Failed (5 lesions) & $\mathbf{p}$ \\
\hline Type C lesion & $4(8)$ & $3(60)$ & 0.013 \\
Severe tortuosity & $2(4)$ & $3(60)$ & 0.004 \\
Angulation $>90^{\circ}$ & $2(4)$ & $3(60)$ & 0.004 \\
Irregular contour & $24(29)$ & $1(20)$ & 1.0 \\
Eccentric shape & $16(33)$ & $1(20)$ & 1.0 \\
Total occlusion & $21(44)$ & $3(60)$ & 0.6 \\
Thrombus in target lesion & $31(64)$ & $3(60)$ & 1.0 \\
\hline
\end{tabular}

Data are presented as number (percentage).

In the direct implantation group the procedural and radiation times were significantly shorter and the amount of contrast and radiation dose were significantly lower, compared to patients from the conventional scaffold implantation group (Table 4).

Final flow analysis did not show significant differences between both groups, TIMI 3 flow grade was achieved in $98 \%$ of cases in the direct arm and in $94 \%$ of cases in the predilatation group. There was no difference in final cTFC between both groups. No-reflow occurred in one case from the predilatation group. Slow-flow occurred in two patients from the direct implantation arm and in two patients from the predilatation arm. Acute gain was significantly higher in the direct group. There were no significant differences in terms of dissection complications, side branch occlusion, and embolisation (Table 5). STEMI patients presented higher baseline $\% \mathrm{DS}$, with more frequent total occlusion and thrombus in the target lesion and also higher acute gain and lower \%DS after $\mathrm{PCl}$ compared to NSTEMI patients (Table 6).
During hospitalisation no recurrent $\mathrm{MI}$, scaffold thrombosis, or target lesion revascularisation was reported in either group.

\section{DISCUSSION}

Initially, in the metallic stent era, balloon predilatation was a mandatory procedure before stent deployment. However, aggressive predilatations carry additional risk of plaque disruption, thrombus mobilisation, and distal embolism with subsequent flow deterioration [3]. Despite restoration of epicardial blood flow, tissue reperfusion often remains suboptimal. Over the years, mechanical and pharmacological strategies have been developed to increase myocardial salvage during $\mathrm{PCl}$, including direct stenting, mesh-covered stents, thrombectomy, and glycoprotein Ilb/IIla inhibitors [3]. Several studies showed that direct stent implantation is associated with the reduction of flow disturbances after primary $\mathrm{PCl}$, better ST-segment resolution as well as better survival at 30 days and one year 
Table 4. Procedural characteristics of percutaneous coronary intervention with Absorb deployed directly and after predilatation

\begin{tabular}{|c|c|c|c|}
\hline & Direct (48 lesions) & Predilatation (52 lesions) & p \\
\hline Radial access & $31(65)$ & $31(60)$ & $<0.001$ \\
\hline Procedure time [min] & $28 \pm 11$ & $40 \pm 19$ & 0.003 \\
\hline Fluoroscopy time [min] & $9.6 \pm 5.3$ & $13.9 \pm 8$ & 0.006 \\
\hline Contrast dye used [mL] & $126 \pm 66$ & $163 \pm 77$ & 0.006 \\
\hline Radiation dose [Gy] & $1.08 \pm 0.72$ & $1.33 \pm 0.62$ & 0.039 \\
\hline Glycoprotein Ilb/IIla antagonists & $19(39)$ & $14(27)$ & 0.2 \\
\hline Number of coronary wires & $1.23 \pm 0.42$ & $1.7 \pm 1.0$ & 0.01 \\
\hline Extra-support coronary wires & $1(2)$ & $14(27)$ & $<0.001$ \\
\hline Additional back-up catheters & $23(48)$ & $26(50)$ & 1.0 \\
\hline Scaffold length [mm] & 18 (Q1: 18; Q3: 23) & 23 (Q1: 18; Q3: 28) & 0.016 \\
\hline Scaffold diameter [mm] & 3.5 (Q1: 3; Q3: 3.5) & $3.0(\mathrm{Q} 1: 3 ;$ Q3: 3,5) & 0.1 \\
\hline Scaffold implantation pressure [atm] & 14 (Q1:12; Q3: 16) & 14 (Q1: 12; Q3: 16) & 0.4 \\
\hline Postdilatation balloon diameter [mm] & 3.6 (Q1: 3.2; Q3: 4) & 3.5 (Q1: 3.2; Q3: 4) & 0.3 \\
\hline Postdilatation pressure [atm] & 18 (Q1: 16; Q3: 20) & 18 (Q1: 16; Q3: 20) & 0.3 \\
\hline Thrombectomy & $23(48)$ & $7(13)$ & $<0.001$ \\
\hline
\end{tabular}

Data are presented as number (percentage), mean \pm standard deviation, or median (interquartile range).

Table 5. Final angiographic results of percutaneous coronary intervention with Absorb implanted directly and after predilatation

\begin{tabular}{|lccc|} 
& Direct (48 lesions) & Predilatation (52 lesions) & p \\
\hline Acute gain [mm] & $1.89 \pm 0.7$ & $1.59 \pm 0.7$ & 0.036 \\
Acute recoil [mm] & $0.32 \pm 0.23$ & $0.29 \pm 0.20$ & 0.8 \\
Diameter stenosis [\%] & $12.2 \pm 6.1$ & $12.7 \pm 7.6$ & 0.7 \\
TIMl 3 flow grade & $47(98)$ & $49(94)$ & 0.5 \\
Corrected TIMl frame count & $16(\mathrm{Q} 1: 12 ;$ Q3: 22) & 18 (Q1: 14; Q3: 24) & 0.3 \\
Slow-flow & $2(4)$ & $2(4)$ & 1.0 \\
No-reflow & $0(0)$ & $1(2)$ & 1.0 \\
Side branch occlusion & $1(2)$ & $1(2)$ & 1.0 \\
Side branch embolisation & $1(2)$ & $1(2)$ & 1.0 \\
Distal embolisation & $0(0)$ & $1(2)$ & 1.0 \\
Dissection & $3(6)$ & $8(15)$ & 0.2 \\
Bail-out stenting & $2(4)$ & $6(12)$ & 0.3 \\
\hline
\end{tabular}

Data are presented as number (percentage), mean \pm standard deviation, or median (interquartile range). TIMI — Thrombolysis in Myocardial Infarction

Table 6. Differences between ST-segment elevation myocardial infarction (STEMI) and non-ST-segment elevation myocardial infarction (NSTEMI) groups

\begin{tabular}{|lccc|} 
& STEMI (36 lesions) & NSTEMI (65 lesions) & $p$ \\
\hline Type C lesions & $8(22)$ & $15(23)$ & 1.0 \\
Thrombus in target lesion & $26(72)$ & $24(35)$ & 0.002 \\
Total occlusion & $22(61)$ & $13(20)$ & $<0.001$ \\
Baseline diameter stenosis [\%] & $100(\mathrm{Q} 1: 72 ; \mathrm{Q} 3: 100)$ & $64(\mathrm{Q} 1: 54 ; \mathrm{Q} 3: 83)$ & $<0.001$ \\
Final diameter stenosis [\%] & $10 \pm 7$ & $13 \pm 7$ & 0.036 \\
Final TIMI 3 flow grade & $34(94)$ & $62(95)$ & 1.0 \\
Acute gain [mm] & $2.1 \pm 0.6$ & $1.6 \pm 0.7$ & $<0.001$ \\
Acute recoil [mm] & $0.32 \pm 0.20$ & $0.30 \pm 023$ & 0.8 \\
\hline
\end{tabular}

Data are presented as number (percentage), mean \pm standard deviation, or median (interquartile range). TIMI — Thrombolysis in Myocardial Infarction 
[7-10]. Another strategy designed to reduce distal embolisation is the use of a MGuard ${ }^{\mathrm{TM}}$ bare metal mesh-covered stent, which traps the potentially embolic material at the level of the culprit lesion. However, the use of mesh-covered stents is limited due to lack of anti-proliferative drugs. They should also be avoided in bifurcation and highly tortuous or calcified lesions [3, 11]. Routine thrombectomy is currently not recommended in primary $\mathrm{PCl}$, but in the presence of large thrombotic burden it may be considered, also with the direct stenting technique [12,13]. Glycoprotein IIb/IIla inhibitors are strong antiplatelet agents, which could be used in patients with high risk of ischaemic events (large thrombotic burden) and angiographic complications (distal embolisation, no-reflow phenomenon) [14].

Currently, direct DES implantation is a preferable technique for primary $\mathrm{PCl}$ in the ACS setting in suitable coronary anatomy. However, the permanent metallic platform of regular DESs also has some limitations, including impaired vasomotion, reduced potential for vessel remodelling, chronic inflammation processes, and late thrombosis [15]. BVSs were designed to target the limitations of regular DESs with restored vasomotion, arterial remodelling, and late lumen enlargement $[16,17]$. Nevertheless, recent data show inferiority of Absorb BVS, compared to regular DES, with higher rates of scaffold thrombosis (probably due to late scaffold discontinuity leading to disruption of laminar flow), possible thrombogenicity of breakdown products, and local inflammation processes occurring after resorption of the scaffold [18]. Data from two studies, ABSORB III and AIDA, showed higher rates of probable/definite scaffold thrombosis in the BVS group compared to the everolimus-eluting stent arm at one and two years of follow-up $[19,20]$. Results of the ABSORB II study showed that vasomotor reactivity after three years was not significantly different from the regular DES arm; also, the late lumen loss was greater in the Absorb group [21]. Currently Absorb is not recommended in regular clinical use [18]. A Polish consensus statement on bioresorbable scaffolds also advised against the use of Absorb in routine practice [22]. On the other hand, other scaffolds built of polylactic acid and magnesium have the same strut thickness as the Absorb and are approved for clinical use; therefore, we think that the presented analysis is currently relevant. Nevertheless, a new generation of BVSs with thinner struts and rounder strut cross-section, minimising flow disturbances is being sought. The current Absorb generation presents struts of $152 \mu \mathrm{m}$ and a crossing profile of $1.4 \mathrm{~mm}$. Due to increased strut thickness, larger crossing profile, and the device's lower penetrating force into the plaque, predilatation was recommended before scaffold deployment. Data about direct BVS implantation technique are scarce. In earlier studies, direct stenting with Absorb was performed, ranging from $9 \%$ in a Polish registry to $44 \%$ in a randomised TROFI trial $[23,24]$. In a Spanish study that included both stable coronary artery disease and ACS patients, direct scaf- fold implantation was attempted in 150 lesions [4]. Successful BVS delivery was achieved in $86 \%$ of cases in the direct arm. Longer, C-type lesions and a larger plaque burden were associated with failure in Absorb implantation in that analysis [4]. Another study included a retrospective overview of nine ACS patients treated with direct BVS implantation. Scaffolds were successfully implanted in all patients [5]. In our analysis type $\mathrm{C}$ lesions with severe tortuosity and angulation $>90^{\circ}$ were associated with failure in direct Absorb deployment.

Outcomes of Absorb implantation vary depending on the centre's and operator's experience, implantation technique, and use of intravascular imaging tools [25]. Standard BVS-specific implantation protocol includes predilatation with a non-compliant balloon up to the size of the RVD, implantation of the Absorb of the same size as the RVD, and high-pressure postdilatation for optimal scaffold apposition, with a non-compliant balloon of the same diameter as the RVD or $0.5 \mathrm{~mm}$ larger $[26,27]$. On the other hand, overexpansion might lead to strut fracture, so the size of the postdilatation balloon should not exceed the scaffold diameter by more than $0.5 \mathrm{~mm}$. For this reason, precise vessel/scaffold sizing should be performed, preferably with OCT, which also allows accurate assessment of scaffold apposition [22]. Optimal vessel selection is also important, as an RVD of $<2.25 \mathrm{~mm}$ has been identified as a predictor of scaffold thrombosis after Absorb implantation [19]. However, due to limited availability and high costs, OCT is generally underused. In our registry, only visual estimations were applied, which is a typical clinical approach in the ACS all-comer populations. In the presented study scaffolds were implanted by highly skilled operators with experience in BVS implantation in both ACS and stable coronary disease patients, with use of IVUS and OCT, and the BVS-specific implantation protocol with high-pressure postdilatation was implemented. The median postdilatation balloon diameter was $3.6 \mathrm{~mm}$ in the direct group and $3.5 \mathrm{~mm}$ in the predilatation group, whereas baseline reference vessel diameters were 2.8 and $2.7 \mathrm{~mm}$, respectively. Median scaffold diameter was $3.5 \mathrm{~mm}$ in the direct group and $3.0 \mathrm{~mm}$ in the predilatation arm.

The most important finding of the presented analysis is the feasibility and good immediate angiographic results of direct BVS deployment in patients with acute MI. Our registry shows that the procedure of BVS implantation can be effective in a suitable lesion anatomy. Successful Absorb implantation was achieved in $91 \%$ of cases in the direct arm and $98 \%$ of cases in the predilatation group.

The presented analysis was a registry, not a randomised study, but it represents real-world data. The registry sample size is relatively small and the results only allow for hypothesis generation and possible planning of larger randomised studies. The methods used in this study were suboptimal. The presented procedural results were based on angiography and quantitative analysis. The use of IVUS or OCT was not 
obligatory and the decision whether to use it was left to the operator. The value of an angiographic assessment of a scaffold invisible for fluoroscopy is limited and does not provide information about the scaffold apposition. Finally, frequent use of guiding catheters as an additional back-up could have contributed to the high success rates in BVS deliverability in our analysis.

In conclusion, direct Absorb implantation in patients with acute $\mathrm{MI}$ may be effective and feasible in suitable coronary anatomy.

\section{Conflict of interest: none declared}

\section{References}

1. Tanaka A, Jabbour RJ, Latib A, et al. Bioresorbable vascular scaffolds: From patient selection to optimal scaffold implantation; tips and tricks to minimize device failure. Catheter Cardiovasc Interv. 2016; 88(S1): 10-20, doi: 10.1002/ccd.26812, indexed in Pubmed: 27797460.

2. Everaert B, Wykrzykowska JJ, Koolen J, et al. Recommendations for the use of bioresorbable vascular scaffolds in percutaneous coronary interventions: 2017 revision. Neth Heart J. 2017; 25(7-8): 419-428, doi: 10.1007/s12471-017-1014-z, indexed in Pubmed: 28643297.

3. Ndrepepa G, Kastrati A. Mechanical strategies to enhance myocardial salvage during primary percutaneous coronary intervention in patients with STEMI. EuroIntervention. 2016; 12(3): 319-328, doi: 10.4244/EIJV12I3A52, indexed in Pubmed: 27320426 .

4. Suárez de Lezo J, Martín P, Mazuelos F, et al. Direct bioresorbable vascular scaffold implantation: Feasibility and midterm results. Catheter Cardiovasc Interv. 2016; 87(5): E173-E182, doi: 10.1002/ccd.26133, indexed in Pubmed: 26268440.

5. Sultan A, Randhawa V, Camuglia AC, et al. Short-term outcomes in patients with acute coronary syndrome treated with direct bioresorbable scaffold deployment. Cardiovasc Revasc Med. 2015; 16(7): 381-385, doi: 10.1016/j.carrev.2015.06.007, indexed in Pubmed: 26242563.

6. Bonow RO, Masoudi FA, Rumsfeld JS, et al. ACC/AHA classification of care metrics: Performance measures and quality metrics: A report of the American College of Cardiology/American Heart Association Task Force on Performance Measures. J Am Coll Cardiol. 2008; 52(24): 2113-2117, doi: 10.1161/CIRCULATIONAHA.108.191107.

7. Möckel M, Vollert J, Lansky AJ, et al. Comparison of direct stenting with conventional stent implantation in acute myocardial infarction. Am J Cardiol. 2011; 108(12): 1697-1703, doi: 10.1016/j.amjcard.2011.07.040, indexed in Pubmed: 21906709.

8. McCormick LM, Brown AJ, Ring LS, et al. Direct stenting is an independent predictor of improved survival in patients undergoing primary percutaneous coronary intervention for ST elevation myocardial infarction. Eur Heart J Acute Cardiovasc Care. 2014; 3(4): 340-346, doi: 10.1177/2048872614530864, indexed in Pubmed: 24719243.

9. Li C, Zhang B, Li M, et al. Comparing direct stenting with conventional stenting in patients with acute coronary syndromes: a meta-analysis of 12 clinical trials. Angiology. 2016; 67(4): 317-325, doi: 10.1177/0003319715585662, indexed in Pubmed: 25964649.

10. Dziewierz A, Siudak Z, Rakowski T, et al. Impact of direct stenting on outcome of patients with ST-elevation myocardial infarction transferred for primary percutaneous coronary in- tervention (from the EUROTRANSFER registry). Catheter Cardiovasc Interv. 2014; 84(6): 925-931, doi: 10.1002/ccd.25266, indexed in Pubmed: 24155092.

11. Dudek D, Dziewierz A, Kleczyński P, et al. Long-term follow-up of mesh-covered stent implantation in patients with ST-segment elevation myocardial infarction. Kardiol Pol. 2014; 72(2): 140-145, doi: 10.5603/KP.a2013.0252, indexed in Pubmed: 24142749.

12. Ibanez B, James S, Agewall S, et al. 2017 ESC Guidelines for the management of acute myocardial infarction in patients presenting with ST-segment elevation. Kardiol Pol. 2018; 76(2): 229-313, doi: 10.5603/kp.2018.0041.

13. Dudek D, Mielecki W, Burzotta F, et al. Thrombus aspiration followed by direct stenting: a novel strategy of primary percutaneous coronary intervention in ST-segment elevation myocardial infarction. Results of the Polish-Italian-Hungarian RAndomized ThrombEctomy Trial (PIHRATE Trial). Am Heart J. 2010; 160(5): 966-972, doi: 10.1016/j.ahj.2010.07.024, indexed in Pubmed: 21095287.

14. Dziewierz A, Rakowski T, Dudek D. Abciximab in the management of acute myocardial infarction with ST-segment elevation: evidence-based treatment, current clinical use, and future perspectives. Ther Clin Risk Manag. 2014; 10: 567-576, doi: 10.2147/TCRM.S50002, indexed in Pubmed: 25071373.

15. Stettler C, Wandel S, Allemann S, et al. Outcomes associated with drug-eluting and bare-metal stents: a collaborative network meta-analysis. Lancet. 2007; 370(9591): 937-948, doi: 10.1016/S0140-6736(07)61444-5, indexed in Pubmed: 17869634 .

16. Depukat R, Rzeszutko L, Dudek D. Regeneration of vessel wall functionality and vascular restoration therapy with biodegradable stents -- current status. Curr Pharm Biotechnol. 2012; 13(13): 2440-2448, doi: 10.2174/13892010112080624 40, indexed in Pubmed: 22280418.

17. Iqbal J, Onuma Y, Ormiston J, et al. Bioresorbable scaffolds: rationale, current status, challenges, and future. Eur Heart J. 2014; 35(12): 765-776, doi: 10.1093/eurheartj/eht542, indexed in Pubmed: 24366915.

18. Byrne RA, Stefanini GG, Capodanno D, et al. Report of an ESC-EAPCI Task Force on the evaluation and use of bioresorbable scaffolds for percutaneous coronary intervention: executive summary. EuroIntervention. 2018; 13(13): 1574-1586, doi: 10.4244/EIJ20170912-01, indexed in Pubmed: 28948934.

19. Wykrzykowska JJ, Kraak RP, Hofma SH, et al. Bioresorbable Scaffolds versus Metallic Stents in Routine PCI. N Engl J Med. 2017; 376(24): 2319-2328, doi: 10.1056/NEJMoa1614954, indexed in Pubmed: 28402237.

20. Ellis SG, Kereiakes DJ, Metzger DC, et al. Everolimus-Eluting bioresorbable scaffolds for coronary artery disease. N Engl J Med. 2015; 373(20): 1905-1915, doi: 10.1056/NEJMoa1509038, indexed in Pubmed: 26457558.

21. Serruys PW, Chevalier B, Sotomi Y, et al. Comparison of an everolimus-eluting bioresorbable scaffold with an everolimus-eluting metallic stent for the treatment of coronary artery stenosis (ABSORB II): a 3 year, randomised, controlled, single-blind, multicentre clinical trial. Lancet. 2016; 388(10059): 2479-2491, doi: 10.1016/S0140-6736(16)32050-5, indexed in Pubmed: 27806897.

22. Reczuch K, Milewski K, Wąsek W, et al. [Bioresorbable scaffolds in the treatment of coronary artery disease. Expert consensus statement of the Association of Cardiovascular Interventions of the Polish Cardiac Society (ACVI PCS)]. Kardiol Pol. 2017; 75(8): 817-835, doi: 10.5603/KP.2017.0160, indexed in Pubmed: 28819961.

23. Rzeszutko Ł, Siudak Z, Włodarczak A, et al. Use of bioresorbable vascular scaffolds in patients with stable angina and 
acute coronary syndromes. Polish National Registry. Kardiol Pol. 2014; 72(12): 1394-1399, doi: 10.5603/KP.a2014.0147, indexed in Pubmed: 25001567.

24. Sabaté M, Windecker S, Iñiguez A, et al. Everolimus-eluting bioresorbable stent vs. durable polymer everolimus-eluting metallic stent in patients with ST-segment elevation myocardial infarction: results of the randomized ABSORB ST-segment elevation myocardial infarction-TROFI II trial. Eur Heart J. 2016; 37(3): 229-240, doi: 10.1093/eurheartj/ehv500, indexed in Pubmed: 26405232.

25. Imori Y, D'Ascenzo F, Gori T, et al. Impact of postdilatation on performance of bioresorbable vascular scaffolds in patients with acute coronary syndrome compared with everolimus-eluting stents: A propensity score-matched analysis from a multicenter "real-world" registry. Cardiol J. 2016; 23(4): 374-383, doi: 10.5603/CJ.a2016.0052, indexed in Pubmed: 27515481.

26. Stone GW, Abizaid A, Onuma Y, et al. Effect of technique on outcomes following bioresorbable vascular scaffold implantation: analysis from the ABSORB trials. J Am Coll Cardiol. 2017; 70(23): 2863-2874, doi: 10.1016/j.jacc.2017.09.1106, indexed in Pubmed: 29100704.

27. Dziewierz A, Dudek D. Current perspectives on the role of bioresorbable scaffolds in the management of coronary artery disease. Kardiol Pol. 2018; 76(7): 1043-1054, doi: 10.5603/KP.a2018.0130.

Cite this article as: Rzeszutko $€$, Węgiel M, Kleczyński P, et al. Direct Absorb bioresorbable scaffold implantation in acute coronary syndrome. Kardiol Pol. 2018; 76(10): 1434-1440, doi: 10.5603/KP.a2018.0147.

\section{WHAT IS NEW?}

In the presented study we show the feasibility and high success rate of direct implantation of the Absorb bioresorbable vascular scaffold in patients with acute coronary syndrome. No significant differences were observed in final flow analyses and angiographic complications between patients treated with direct Absorb deployment and conventional implantation after predilatation. Direct stenting is a preferred technique for primary percutaneous coronary intervention with a regular drug-eluting stent, with several studies showing better immediate and long-term outcomes compared to stent implantation after predilatation. Absorb scaffolds have thicker struts and a larger crossing profile; therefore, for successful scaffold delivery and deployment elective predilatation was initially recommended. So far there has been no specific analysis of direct Absorb implantation technique in patients with acute coronary syndrome. 